\title{
Lissencephaly- a rare cause of neonatal seizures
}

\author{
Wali P.P. ${ }^{1}$, Parakh H. ${ }^{2}$, Reddy K. ${ }^{3}$, Reddy P. ${ }^{4}$ \\ ${ }^{1}$ Dr. Pradnya P. Wali, Junior Consultant, Neonatologist, ${ }^{2}$ Dr. Hemant Parakh, Consultant, Neonatologist, Sunrise \\ Children Hospital, ${ }^{3}$ Dr. Krishna Reddy, Consultant, Pediatrician, Krishna Children Hospital, ${ }^{4}$ Dr. Prashant Reddy, \\ Consultant, Pediatrician, Sunrise Children Hospital, Hyderabad, India.
}

Corresponding Author: Dr. Hemant Parakh, Consultant, Neonatologist, Sunrise Children Hospital, Hyderabad, India. Email: drhemantparakh@gmail.com

\begin{abstract}
The most prominent feature of neurologic dysfunction in the neonatal period is seizures. The incidence of neonatal seizures is $0.5-3$ per 1000 live births in term infants and $11-13 \%$ in premature babies. Although common causes of neonatal seizures comprises HIE, IVH, Sepsis, Hypoglycaemia, Hypocalcaemia etc. Sometimes rare causes like Neuronal migration syndrome can cause seizures in newborn. Lissencephaly is a smooth cerebrum with lack of convolutions of brain caused by defective neuronal migration during 12- 24 weeks of gestation. These Babies generally presents with seizures, developmental delay, difficulty in swallowing and short life span due to respiratory problems. Hereby we present a case of Lissencephaly as a cause of neonatal seizure disorder.
\end{abstract}

Keywords: Neonatal seizures, Neuronal migration disorder, Lissencephaly

\section{Introduction}

Neonatal seizures represent one of the most frequent neurological events in newborn infants, often reflecting a variety of different pre-, peri-, or postnatal disorders of the central nervous systems. The neonatal period is the most vulnerable of all periods of life for developing seizures, particularly in the first 1-2 days to the first week from birth. The prevalence is approximately $1.5 \%$ and overall incidence approximately 3 per 1000 live births. Most $(80 \%)$ neonatal seizures occur in the first 1-2 days to the first week of life. The etiology of neonatal seizures is extensive and diverse. HIE, IVH, infections, metabolic disturbances like hypoglycemia, hypocalcemia are major causes of neonatal seizures. Sometimes rare causes like brain malformations and IEM can lead to seizures in newborn. Brain malformations including neuronal migration syndromes constitutes for $4 \%$ of etiology of neonatal seizures and hence should be considered during the evaluation of newborn with seizure disorder. Neuroimaging like NSG \& MRI brain can help in the diagnosis. Prognosis generally depends on the severity of the disease.

\section{Case Report}

A Term AGA male baby weighing $3.56 \mathrm{kgs}$ born by LSCS to G4P1L1A2 mother was admitted at 3 hours of life with complaints of Respiratory distress since birth. Mother had h/o polyhydroamnios. Baby did not cry immediately after birth and required resuscitation with tactile stimulation and nasal prong oxygen. Apgar score was $6 \& 8$ at 1 and 5 minutes. At admission baby had tachypnea and retractions. HR -148/min, RR-72/min, SPO2 - 97\% with nasal prong oxygen. Temperature, blood pressures were within normal limits. Respiratory system examination - tachypnea, subcostal and intercostal retractions present. Air entry equal on both sides. Other systems examination was within normal limits. Investigation showed Hb-18 gms/dl, TLC- 22,400/ cu mm, platelets -2.82 lakhs/cu mm. CRP- negative. ABG- normal, Chest X Ray- TTNB. Baby was treated with IV fluids, oxygen, and other supportive care. Small feeds were started and upgraded as baby tolerated feeds. At 36 hours of life baby had jerky movements of right upper limb (right sided focal convulsions). Baby was dull and hypotonic. Head circumference - $34 \mathrm{cms}$. AF- Level and brisk DTRs. Baby was treated with Phenobarbitone loading and half loading (till $40 \mathrm{mg} / \mathrm{kg}$ ) to control seizures. As seizures continued, inj. Levipil was

Manuscript received: $28^{\text {th }}$ August 2018

Reviewed: $6^{\text {th }}$ September 2018

Author Corrected: $14^{\text {th }}$ September 2018

Accepted for Publication: $18^{\text {th }}$ September 2018 
Case Report

added. Seizures were controlled thereafter. Repeat septic screen was negative. Metabolic parameters like GRBS, Sr calcium, Sr. magnesium, Sr. electrolytes, VBG, were normal. NSG done showed large persistent septum cavam pellucidum. EEG- abnormal record with generalized high amplitude sharp $\mathrm{n}$ spike wave complexes. MRI brain showed extensive paucity of sulcation in all lobes in both cerebral hemisphere and broad gyri. Inferior vermian hypoplasia was noted s/o Lissencephaly.
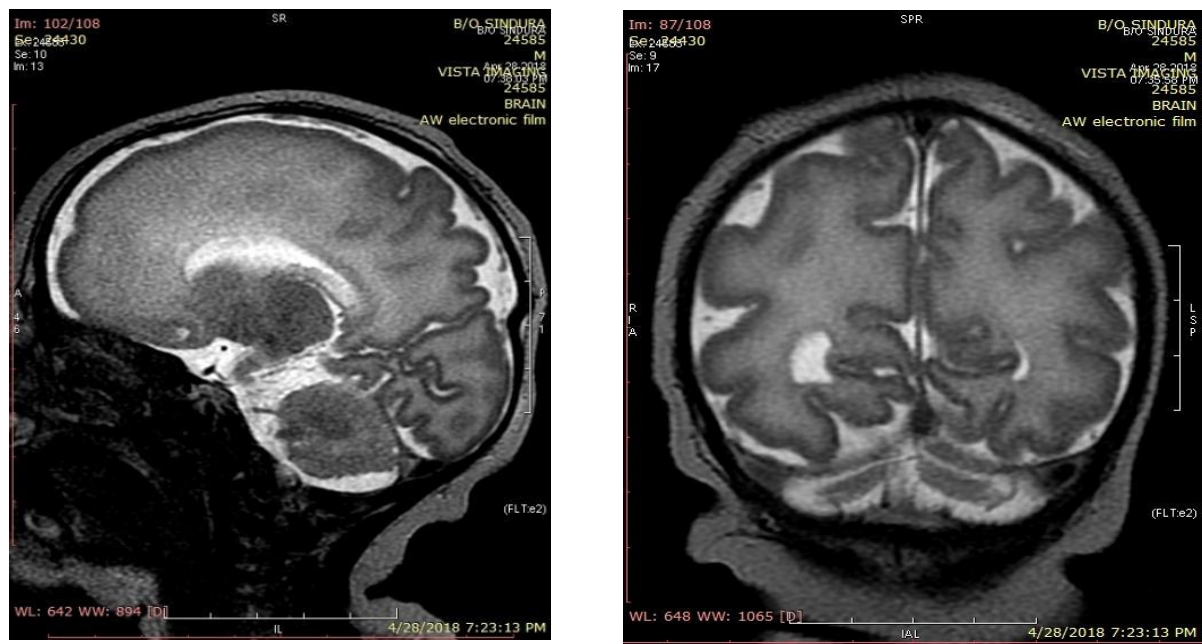

Fig-1 \& 2: MRI brain showed extensive paucity of sulcation in all lobes in both cerebral hemisphere and broad gyri. Inferior vermian hypoplasia was noteds/o Lissencephaly

Torch titers done to rule out congenital infections were negative. Pediatric neurologist opinion was taken who advised to increase nutritional support, physiotherapy and oromotor stimulation. phenobarbitone was tapered and stopped and oral levipil and anti- GERD measures continued. Parents were involved in baby care and physiotherapy. Nature and course of the disease and prognosis was explained in detail to the parents. Baby was discharged in stable condition on paladay feeds. Regular follow up with pediatrician, pediatric neurologist and developmental pediatrician was advised to monitor growth and development.

\section{Discussion}

Cerebral malformations including neuronal migration syndrome accounts for $3-17 \%$ of all causes for neonatal seizures [1]. Neuronal migration disorders are structural malformations in the cerebellum, hippocampus, or cerebral cortex, which result from defects in the migration of newly generated neurons to their target regionat 12- 24 weeks of gestation]. Lissencephaly (LIS, smooth brain) is a neuronal migration disorder that results in mental retardation, epilepsy and when severe a shortened lifespan $[2,3]$.

Lissencephaly isdivided into: Classic lissencephaly (type 1 lissencephaly) and Cobblestone complex (type 2 lissencephaly). Less common types are associated with agenesis of the corpus callosum (ACC) or severe cerebellar hypoplasia $[4,5]$. In classic lissencephaly the integrity of the pial surface is intact, but the cerebral cortex is abnormally thick While in cobble stone form cobble stone like nodules are present over the brain surface as the integrity of pial surface is compromised. Cobblestone complex is often seen as part of multisystem disorders including Walker-Warburg syndrome, muscle-eye-brain disease, and Fukuyamatype congenital muscular dystrophy. In our baby, MRI showed pachygyria with mild vermion hypoplasia with no cobblestone nodules, hence was s/o classical lissencephaly.

Causes of Lissencephaly- viral infections during the first trimester, insufficient blood supply to the fetal brain early in pregnancy, genetic causes including mutation of the reelin gene (on chromosome 7), and other genes on the $\mathrm{X}$ chromosome and on chromosome $17[6,7]$.

Geneticetiology- LIS1on chromo some $17 \mathrm{p} 13.3$ was the first genes identified to cause Lissencephaly [8]. Mutations in this gene are associated with: MillerDieker syndrome (MDS) and isolated lissencephaly sequence (ILS). MDS is characterized by classic lissencephaly with unique facial features (prominent forehead, bitemporal hollowing, short nose with 
Case Report

upturned nares, protuberant upper lip, thin vermilion border, and small jaw) [9]. Classic lissencephaly lacking the characteristic facial features of MDS, is called ILS. The majority of LIS1 mutations are de novo (not inherited from a parent) and hence the recurrence risk is generally low.

Mutation in DCX (doublecortin) gene located on the X chromosome and TUBA1A gene mutation can lead to classical Lissencephaly $[10,11,12]$. Other genes mutations associated with classic lissencephaly include RELN, VLDLR, and ARX and are characterized by generalized pachygyria with severe cerebellar hypoplasia [13]. In our case, baby had generalized pachygyria with mild vermian hypoplasia with no characteristic facial features and hence was suggestive of isolated lissencephaly sequence due to LIS1 mutation on chromosome 17.

Babies generally presents with severe psychomotor retardation, failure to thrive, seizures, Unusual facial appearance and muscle spasticity or hypotonia [14].Our baby presented with seizure disorder but lacked characteristic facial features.

The diagnosis is made by ultrasound (23-25 weeks), CT scan andconfirmed by a prenatal MRI $[15,16]$. If Lissencephaly is suspected, chorionic villus sampling can be done for those with a known genetic mutation.

Treatment is generally symptomatic and supportive. Anticonvulsants for seizure disorder, feeding gastrostomy in cases of feeding difficulty is required. Hydrocephalus may require shunting.

Genetic counseling is recommended for a family of affected children. The prognosis depends on the severity of the malformations. Many babies remain in a 3-5 month developmental level. Life expectancy is short and many die before the age of 10 . Aspiration and respiratory disease are the most common causes of illness or death [17].

\section{Conclusion}

Although rare, neuronal migration syndromes like Lissencephaly can cause seizure disorders in newborn. USG at 23-25 weeks of gestation and fetal MRI may help in prompt diagnosis. Genetic counseling is of great help to parents with affected children.

Hence rare causes like Neuronal migration syndromes should be kept in mind while dealing with neonatal seizure disorders.

\section{Abbreviations}

HIE- Hypoxic ischaemic encephalopathy, IVHIntraventricular hemorrhage, DTR- Deep tendon reflexes, VBG- Venous blood gas, NSG- Neurosonogram, EEG- Electroencephalogram.

Funding: Nil, Conflict of interest: None initiated, Perission from IRB: Yes

\section{References}

1. Vasudevan C, Levene M. Epidemiology and aetiology of neonatal seizures. Semin Fetal Neonatal Med. 2013 Aug;18(4):185-91. doi: 10.1016/j.siny.2013. 05.008. Epub 2013 Jun 5.

2. Dobyns WB, Truwit CL, Ross ME, etal.Differences inthe gyral pattern distinguish chromosome 17-linked and X-linked lissencephaly. Neurology. 1999 Jul 22; 53 (2): $270-7$.

3. Pilz DT, Matsumoto N, Minnerath S, et al. LIS1 and XLIS (DCX) mutations cause most classical lissencephaly, but different patterns of malformation. Hum Mol Genet. 1998 Dec;7(13):2029-37.

4. Dobyns WB, Berry-Kravis E, Havernick NJ, et al. Xlinked lissencephaly with absent corpus callosum and ambiguous genitalia. Am J Med Genet. 1999 Oct 8;86 (4): $331-7$.

5. Ross ME, Swanson K, Dobyns WB. Lissencephaly with cerebellar hypoplasia ( $\mathrm{LCH})$ : a heterogeneous group of cortical malformations. Neuropediatrics. 2001 Oct;32(5):256-63. doi:10.1055/s-2001-19120

6. Leena, Dennis Joseph; Pushpalatha; Kuruvilla, Sarah. Cytomegalovirus infection with lissencephaly". Indian J Pathol Microbiol. 2008; 51 (3): 402-4. doi:10.4103/ 0377-4929.42534.

7. Hong SE, Shugart YY, Huang DT, et al. Autosomal recessive lissencephaly with cerebellar hypoplasia is associated with human RELN mutations". Nat. Genet. 2000; 26 (1): 93-6. doi:10.1038/79246.

8. Reiner $\mathrm{O}$, Carrozzo $\mathrm{R}$, Shen $\mathrm{Y}$, et al. Isolation of a Miller-Dieker lissencephaly gene containing $\mathrm{G}$ protein beta-subunit-like repeats. Nature. 1993 Aug 19; 364 (6439): 717-21.doi:10.1038/364717a0

9. Dobyns WB, Curry CJ, Hoyme HE, et al. Clinical and molecular diagnosis of Miller-Dieker syndrome. Am J Hum Genet. 1991 Mar;48(3):584-94. 


\section{Case Report}

10. Des Portes V, Pinard JM, BilluartP,etal. A novel CNS gene required for neuronal migration and involved in X-1 inked subcortical laminar heterotopia and lissencephaly syndrome. Cell. 1998 Jan 9;92(1):51-61.

11. Gleeson JG, Allen KM, Fox JW, et al. Doublecortin, a brain-specific gene mutated in human X-linked lissencephaly and double cortex syndrome, encodes a putative signaling protein. Cell. 1998 Jan 9;92(1):63-72.

12. Keays DA, Tian G, Poirier K, et al. Mutations in alpha-tubulin cause abnormal neuronal migration in mice and lissencephaly in humans. Cell. 2007 Jan 12;128(1):45-57. doi:10.1016/j.cell.2006.12.017

13. Kitamura K, Yanazawa M, Sugiyama N, et al. Mutation of ARX causes abnormal development of forebrain and testes in mice and X-linked lissencephaly with abnormal genitalia in humans. Nat Genet. 2002
Nov; 32 (3):359-69. Epub 2002 Oct 15.doi:10. 1038 /ng1009.

14. Jones, KL (2006). Smith's Recognizable Patterns of Human Malformation (6th ed.). Philadelphia: Elsevier Saunders.

15. Aslan H, Gungorduk K, Yildirim D, et al. Prenatal diagnosis of lissencephaly: a case report. J Clin Ultrasound. 2009 May;37(4):245-8. doi: 10.1002/jcu. 20572.

16. Cordes, M; Cordes, I; et al. Lissencephaly: Diagnosis by computed tomography and magnetic resonance imaging. Eur J Radiol. 1898;8 (2): 131-3.

17. Baker, Lisa. Lissencephaly. The Resource Foundation for Children with Challenges. Archived from the original on 2 June 2013. Retrieved 10 May 2013.

\section{How to cite this article?}

Wali P.P, Parakh H, Reddy K, Reddy P. Lissencephaly- a rare cause of neonatal seizures. Int J Pediatr Res.2018; 5(9):480-483. doi:10.17511/ijpr.2018.i09.09. 